\title{
A cross sectional study to assess pharmacotherapeutic adherence among diabetes mellitus patients in tertiary care hospital
}

\author{
Richa Gaur ${ }^{1}$, Virendra Kushwaha ${ }^{1 *}$, Pooja Agrawal', Saurabh Agrawal', \\ Amit Kumar ${ }^{1}$, Kriti Malhotra ${ }^{1}$
}

${ }^{1}$ Department of Pharmacology, ${ }^{2}$ Department of Medicine, G.S.V.M. Medical College, Kanpur, Uttar Pradesh, India

Received: 16 November 2018 Accepted: 28 December 2018

\section{*Correspondence to:}

Dr. Virendra Kushwaha, Email: vkushwaha1970@ gmail.com

Copyright: (C) the author(s), publisher and licensee Medip Academy. This is an openaccess article distributed under the terms of the Creative Commons Attribution NonCommercial License, which permits unrestricted noncommercial use, distribution, and reproduction in any medium, provided the original work is properly cited.

\begin{abstract}
Background: Diabetes mellitus (DM) refers to a group of common metabolic disorders that associated with abnormalities in carbohydrate, fat, and protein metabolism which results in chronic complications. Attainment of optimal blood sugar level is generally based on appropriate usage and proper adherence to prescribed medications. The study was, therefore, aimed to assess adherence to oral antidiabetic drugs among diabetic patients attending outpatient clinic of L. L. R. Hospital, G.S.V.M. Medical College, Kanpur, U.P.

Methods: Hospital based cross-sectional study design was conducted from April 2017 to June 2018. The data was collected by interviewing T2DM patients receiving antidiabetic medications using Morisky's four item adherence assessment questionnaire. The collected data was processed and analyzed with SPSS version 20.

Results: From the 126 patients of diabetes, when asked about adherence to their medications as per the Morisky's four item method, $114(90.47 \%)$ of them did not forget to take the drugs, $108(85.71 \%)$ of patients reported that they had been being careful in taking their medications, $90(71.42 \%)$ patients did not stop medications when they felt better and the other $108(85.71 \%)$ patients reported that they did not stop medications when they felt worse while taking medications. This study shows that $54(42.86 \%)$ respondents were adherent to their medications.

Conclusions: This study revealed a moderate level of adherence among the participants and statistically significantly depended upon their socioeconomic status. Efforts are needed to increase the medication adherence of these patients', so they can realize the full advantage of prescribed therapies.
\end{abstract}

Keywords: Morisky's scale,Pharmacotherapeutic adherence, Type 2 diabetes mellitus

\section{INTRODUCTION}

According to the WHO (2003) adherence to treatment is defined as the extent to which a patient's behavior: taking medication, following a diet, or making healthy lifestyle changes, corresponds with agreed-upon recommendations from a health-care provider. ${ }^{1}$

Globally, an estimated 422 million adults are living with diabetes mellitus, according to the latest 2016 data from the World Health Organization. ${ }^{2}$ Diabetes prevalence is increasing rapidly; previous 2013 estimates from the
International Diabetes Federation put the number at 381 million people having diabetes. ${ }^{3}$ The number is projected to almost double by $2030 .{ }^{4}$ Diabetes currently affects more than 62 million Indians, which is more than $7.1 \%$ of the adult population. ${ }^{5}$

Type 2 diabetes mellitus (DM) is a chronic disease that usually co-exists with other medical conditions. Uncontrolled DM leads to various short-term as well as long term, microvascular and macrovascular complications. Hence, the patient may be taking multiple medications to treat several coexisting conditions. This 
creates a complex situation wherein the patient has to be on multiple drug therapy with complicated dosing schedules that is likely to result in low adherence to the medication plan. ${ }^{6}$

According to the WHO, non-adherence to the medical regimen consist a major clinical problem in the management of patients with chronic illness. ${ }^{7}$

Optimal glucose control can be achieved through strict adherence to medications, diet and life style modifications that in turn minimizes long-term complications. ${ }^{8}$

Therefore, the purpose of this study is to assess Medication Adherence and reasons associated with Non-adherence to anti-diabetic therapy which will help the Physicians in making decisions to reduce the nonadherence.

\section{METHODS}

Study was conducted by department of pharmacology in collaboration with the department of internal medicine at a tertiary-care teaching hospital over a period of 15 months commencing from April 2017 to June 2018. The present study was cross-sectional study. The patients who attended the outpatient clinic of Lala Lajpat Rai Hospital (L.L.R. Hospital), G.S.V.M. Medical College, Kanpur, U.P. diagnosed with type-2 Diabetes Mellitus were included in this study. Patients were included after evaluating for inclusion and exclusion criteria. The written informed consent was taken from each patient before enrollment in the study. The study was started after getting the ethical clearance from institutional ethics committee.

\section{Inclusion criteria}

- Subjects who were on prescription medications for type 2 diabetes mellitus

- Subjects of age above 18years were included

- Subjects of taking medication for more than 1 month were included.

\section{Exclusion criteria}

- $\quad$ Subjects of age less than 18years were excluded

- New diagnosed patients were excluded

- Subjects of taking medication for less than 1 month were excluded.

- Patients who were very ill and not able to answer the question were excluded from the study

- Study subjects who were taking other forms of medications (Ayurvedic and Homeopathic)

- Subjects with hearing/cognitive impairment were excluded

This study was a community based, cross sectional, observational study. All patients with type-2 Diabetes Mellitus fulfilling inclusion and exclusion criteria attending the diabetes OPD were included in the study. 150 patients were screened and among them 130 patients were eligible for present study. Out of 130 patients, 4 patients did not give the consent. Finally, 126 patients were enrolled in the current study.

The selected patients were interviewed regarding their socio-demographic characteristics, income, duration of drug intake and reasons for nonadherence to medicine by using a preformed questionnaire. The study subjects were grouped into the socioeconomic classes modified Kuppuswamy scale for 2018 for urban population and modified B.G. Prasad scale for rural population. The questions were translated and explained to the patients in Hindi language.

Before assessment of adherence in patients, we excluded the patients suffer from depression, anxiety, stress as per DASS scale. Adherence was assessed through the specific four question patient questionnaire related the Morisky's instrument that has high reliability and validity and patient is considered to be adherent if he/she answered in the negative to all four questions.

\section{Statistical analysis}

The data was compiled and converted in the form of tables and graphs using Microsoft Excel sheet. Compiled data was analyzed using SPSS 20.0. All categorical variables were analyzed using percentage. Quantitative variables were analyzed using Mean, Standard Deviation (SD) and chi square test. Chi square test was used to assess the significance of association between the groups. A p value of 0.05 or less was considered statistically significant.

\section{RESULTS}

The present study was conducted at internal medicine department and department of pharmacology in G.S.V.M. Medical College, Kanpur. This study has been conducted on 126 patients diagnosed with type- 2 diabetes mellitus.

\section{Socio-demographic variables in diabetic patients}

Total of 126 diabetes patients were involved in this study. The response rate was $100 \%$. Among the total of 126 respondents, $76(37.62 \%)$ were males and $50(39.68 \%)$ were females. In males mean age was $54.0 \pm 10.3$ years and in females mean age was $51.8 \pm 10.0$ years. Majority of patients were of age group 41-60years i.e. $62.70 \%$. patients of age group $>60$ years were $26.98 \%$ and patients of age group 18-40years were $10.32 \%$.

Large proportion of patients $83.33 \%$ were urban with residence. Among the urban population, as per Kuppuswamy classification, majority of patients i.e. $63.5 \%$, belongs to Socio- economic Class IV. $30.77 \%$ belongs to Socio- economic Class III. $15.38 \%$ belongs to Socio- economic class II. In rural population as per B.G. Prasad classification major patients i.e. $80.96 \%$ belongs to Socio- economic class II and $19.04 \%$ belongs to Socio- 
economic class I. Nearly half i.e. $46.83 \%$ of the patients had been diagnosed diabetes within the duration of 5 years, $34.92 \%$ of the patients had been diagnosed diabetes within the duration of 5-10years of duration and $18.25 \%$ of the patients had been diagnosed diabetes within the duration of more than 10 years (Table 1 ).

Table 1: Socio-demographic variables in diabetic patients.

\begin{tabular}{|lll|}
\hline Variables & $(\mathbf{n = 1 2 6 )}$ & Percentage \\
\hline Gender & \multicolumn{1}{l}{} \\
\hline Male & 76 & $37.62 \%$ \\
\hline Female & 50 & $39.68 \%$ \\
\hline Age group & & \\
\hline 18-40 years & 13 & $10.32 \%$ \\
\hline 41-60 years & 79 & $62.70 \%$ \\
\hline$>60$ years & 34 & $26.98 \%$ \\
\hline Residence & & \\
\hline Urban & 105 & $83.33 \%$ \\
\hline Rural & 21 & $16.67 \%$ \\
\hline Total & 126 & \\
\hline Duration of disease & & \\
\hline 0-5years & 59 & $46.83 \%$ \\
\hline 5-10years & 44 & $34.92 \%$ \\
\hline$>10 y e a r s$ & 23 & $18.25 \%$ \\
\hline Socioeconomic status & \\
\hline Kuppuswamy scale (urban) & \\
\hline Class I (upper) & 0 & $0 \%$ \\
\hline Class II (upper middle) & 16 & $19.04 \%$ \\
\hline Class III (lower middle) & 32 & $30.77 \%$ \\
\hline Class IV (upper lower) & 56 & $63.85 \%$ \\
\hline Class V (lower) & 0 & $0 \%$ \\
\hline B G Prasad scale (rural) & \\
\hline Class I & 4 & \\
\hline Class II & 18 & \\
\hline
\end{tabular}

Morisky's instrument: question wise percentage of Medication adherence
From the 126 patients of diabetes, when asked about adherence to their medications as per Morisky's four item method, $114(90.47 \%)$ of them did not forget to take the drugs, $108(85.71 \%)$ of patients reported that they had been being careful in taking their medication, 90 (71.42\%) patients did not stop medications when they felt better and the other $108(85.71 \%)$ patients reported that they did not stop medications when they felt worse while taking medications (Table 2). Concerning the overall adherence status, this study shows that $54(42.86 \%)$ respondents were adherent to their medications while $72(57.14 \%)$ of them were nonadherent. The adherence status of each patient was determined based on his/her response to the fouradherence question. Patients who replied "no" to all four questions were categorized as adherent (Table 2).

\section{Morisky's scale to ascertain adherence}

Only $54(42.86 \%)$ of the patients answered 'no' to every question and were considered adherent according to the Morisky's instrument, while $72(57.14 \%)$ of the patients were nonadherent and it was statistically nonsignificant. (Table 3) (Figure 1).

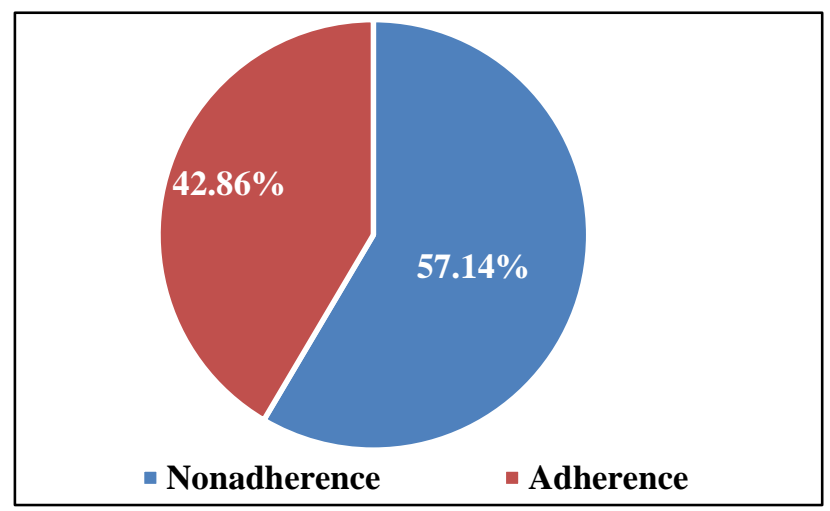

Figure 1: Respondents level of medication adherence among type II diabetes.

Table 2: Morisky's instrument: question wise percentage of medication adherence.

\begin{tabular}{|lll|}
\hline Four-question patient questionnaire (Morisky's instrument) & $\begin{array}{l}\text { No. of patients who said } \\
\text { 'No' (n=126) }\end{array}$ & Percentage (\%) \\
\hline Did you ever forget to take your medication? & 114 & $90.47 \%$ \\
\hline Were you careless at times about taking your medication? & 108 & $85.71 \%$ \\
\hline When you felt better, did you sometimes stop taking your medication? & 90 & $71.42 \%$ \\
\hline $\begin{array}{l}\text { Sometimes, if you felt worse when you took your medicine did you } \\
\text { stop taking it? }\end{array}$ & 108 & $85.71 \%$ \\
\hline $\begin{array}{l}\text { The number of patients who said 'No' to all four questions were } \\
\text { considered adherent to the prescribed anti-diabetic treatment }\end{array}$ & 54 & $42.86 \%$ \\
\hline
\end{tabular}

Table 3: Morisky's scale to ascertain adherence.

\begin{tabular}{|llll|}
\hline Nonadherence & Adherence & Chi square value & p value \\
\hline $72(57.14 \%)$ & $54(42.86 \%)$ & 2.56 & $>0.05$ \\
\hline
\end{tabular}

Note 1: $\mathrm{P}<0.05$ significant; Note 2: data analyzed with chi square test. 
Table 4: Patients distribution according to adherence and non-adherence level in different variables among diabetic patients.

\begin{tabular}{|c|c|c|c|c|c|c|c|c|}
\hline & & $\begin{array}{l}\text { Non- } \\
\text { Adherence } \\
(\mathrm{n}=72)\end{array}$ & $\begin{array}{l}\% \text { Non- } \\
\text { adherence }\end{array}$ & $\begin{array}{l}\text { Adherence } \\
(n=54)\end{array}$ & $\begin{array}{l}\% \\
\text { Adherence }\end{array}$ & $\begin{array}{l}\text { Total } \\
(n=126)\end{array}$ & $\begin{array}{l}\text { Chi } \\
\text { square } \\
\text { value }\end{array}$ & $\begin{array}{l}\mathbf{p} \\
\text { value }\end{array}$ \\
\hline \multirow{2}{*}{ Gender } & Male & 41 & $53.95 \%$ & 35 & $46.05 \%$ & 76 & \multirow{2}{*}{0.7986} & \multirow{2}{*}{0.1858} \\
\hline & Female & 31 & $62 \%$ & 19 & $38.00 \%$ & 50 & & \\
\hline \multirow{3}{*}{ Age group } & 18-40years & 5 & $38.46 \%$ & 8 & $61.54 \%$ & 13 & \multirow{3}{*}{2.297} & \multirow{3}{*}{0.3172} \\
\hline & 41-60years & 48 & $60.76 \%$ & 31 & $39.24 \%$ & 79 & & \\
\hline & $>60$ years & 19 & $55.88 \%$ & 15 & $44.12 \%$ & 34 & & \\
\hline \multirow{2}{*}{ Residence } & Urban & 57 & $54.29 \%$ & 48 & $45.71 \%$ & 105 & \multirow{2}{*}{2.1} & \multirow{2}{*}{0.0737} \\
\hline & Rural & 15 & $71.43 \%$ & 6 & $28.57 \%$ & 21 & & \\
\hline \multirow{3}{*}{$\begin{array}{l}\text { Duration of } \\
\text { disease }\end{array}$} & $0-5$ years & 30 & $50.85 \%$ & 29 & $49.15 \%$ & 59 & \multirow{3}{*}{3.0} & \multirow{3}{*}{0.2231} \\
\hline & $5-10$ years & 30 & $68.18 \%$ & 14 & $31.82 \%$ & 44 & & \\
\hline & $>10$ years & 12 & $52.17 \%$ & 11 & $47.83 \%$ & 23 & & \\
\hline \multirow{3}{*}{$\begin{array}{l}\text { Kuppuswamy } \\
\text { Scale (urban) }\end{array}$} & $\begin{array}{l}\text { Class II (upper } \\
\text { middle) }\end{array}$ & 5 & $31.25 \%$ & 11 & $68.75 \%$ & 16 & \multirow{3}{*}{7.266} & \multirow{3}{*}{0.0264} \\
\hline & $\begin{array}{l}\text { Class III (lower } \\
\text { middle) }\end{array}$ & 15 & $46.87 \%$ & 17 & $53.13 \%$ & 32 & & \\
\hline & $\begin{array}{l}\text { Class IV } \\
\text { (upper lower) }\end{array}$ & 37 & $66.07 \%$ & 19 & $33.93 \%$ & 56 & & \\
\hline \multirow{2}{*}{$\begin{array}{l}\text { B G Prasad } \\
\text { scale (rural) }\end{array}$} & Class I & 3 & $75 \%$ & 1 & $25 \%$ & 4 & \multirow{2}{*}{0.0308} & \multirow{2}{*}{0.4303} \\
\hline & Class II & 12 & $70.59 \%$ & 5 & $29.41 \%$ & 17 & & \\
\hline
\end{tabular}

Note 1: $\mathrm{P}<0.05$ significant; Note 2: data analyzed with chi square test

Table 5: Reasons of pharmacotherapeutic nonadherence among diabetic patients.

\begin{tabular}{|lll|}
\hline $\begin{array}{l}\text { Four-question patient questionnaire (Morisky's } \\
\text { instrument) }\end{array}$ & No. of patients who said ‘yes' & Percentage (\%) \\
\hline Did you ever forget to take your medication? & 12 & $13.52 \%$ \\
\hline Were you careless at times about taking your medication? & 18 & $13.09 \%$ \\
\hline $\begin{array}{l}\text { When you felt better, did you sometimes stop taking your } \\
\text { medication? }\end{array}$ & 36 & $28.86 \%$ \\
\hline $\begin{array}{l}\text { Sometimes, if you felt worse when you took your medicine } \\
\text { did you stop taking it? }\end{array}$ & 18 & $14.34 \%$ \\
\hline
\end{tabular}

\section{Patients distribution according to adherence and non- adherence level in different variables among diabetic patients}

From the 126 patients of diabetes, prevalence of nonadherence and adherence according to Morisky's scale was $41(53.95 \%)$ and $35(46.05 \%)$ respectively in males; $31(62 \%)$ and $19(38 \%)$ in females but the difference was not statistically significant ( $\mathrm{p}>0.05$ ). 18-40years age group had nonadherence i.e. $38.46 \%$ and adherence i.e. $61.54 \%$, 41-60years of age group had nonadherence i.e. $60.76 \%$ and adherence i.e. $39.24 \%$, >60years of age group had nonadherence i.e. $55.88 \%$ and adherence i.e. $44.12 \%$ but the difference was not statistically significant ( $\mathrm{p}>0.05)$.

As per residence, urban population had nonadherence i.e. $54.29 \%$ and adherence i.e. $45.71 \%$ and rural population had nonadherence i.e. $71.43 \%$ and adherence i.e. $28.57 \%$ but the difference was not statistically significant ( $p>0.05)$.
Among the urban population, as shown in the table, as per Kuppuswamy classification, majority of patients belongs to Socio- economic class II had nonadherence level i.e. $33.25 \%$, class III had nonadherence level i.e. $46.87 \%$, class IV had nonadherence level i.e. $66.07 \%$ and class II had adherence level i.e. $68.75 \%$, class III had adherence level i.e. $53.13 \%$, class IV had adherence level i.e. $33.93 \%$ here the difference was statistically significant $(p<0.05)$. In rural population as per B.G. Prasad classification class I had nonadherence level i.e. $75 \%$ and class II had nonadherence level i.e. $70.59 \%$ and adherence level in class I i.e. $25 \%$ and in class II i.e. $29.41 \%$ but the difference was not statistically significant $(\mathrm{p}>0.05)$

As regards the duration of diagnosed diabetes, patients who had been diagnosed within the duration of 5years were $50.85 \%$ nonadherent, patients who had been diagnosed within the duration of 5-10years were $64.44 \%$ nonadherent and patients who had been diagnosed for $>10$ years were 
$52.17 \%$ nonadherent. Patients who had been diagnosed within the duration of 5years of diabetes were $49.15 \%$ adherent, patients who had been diagnosed within the duration of 5-10years were $31.82 \%$ adherent and patients who had been diagnosed for >10years were $47.83 \%$ adherent but the difference was not statistically significant (p >0.05) (Table 4).

\section{Reasons of pharmacotherapeutic nonadherence}

From the perusal of Table 4 it revealed that the reasons for nonadherence out of 126 enrolled diabetic patients were as follows-12 (13.52\%) patients said that they stopped/missed the medication because of forgetfulness; 18 (13.09\%) patients said that they stopped/missed the medication because of carelessness; $36(28.86 \%)$ patients said that they stopped/missed the medication when he or she felt better; $18(14.34 \%)$ patients said that they stopped/missed the medication when he or she felt worse while taking medicines.

The number of patients who said 'yes' to one or more than one of four questions were considered nonadherent to the prescribed treatment (Table 5).

\section{DISCUSSION}

The prevalence of adherence to medications in present study was $42.86 \%$ in diabetes patients. This finding is line with most of previous studies such as Lee CS et al, (42.9\%) in Asian community, Huber CA et al, (40\%) in Switzertand. ${ }^{9,10}$ In comparison to this finding, higher adherence was reported by Navya CJ et al, (76.3\%) in tea estate in south India. ${ }^{11}$ Rao CR et al, reported $83.6 \%$ adherence in type 2 diabetes mellitus patients in Coastal Population of Southern India (Tamil Nadu). ${ }^{12}$ Abebaw M et al, reported $85 \%$ adherence in Ethopia. ${ }^{13}$ Lower percentage of pharmacotherapeutic adherence was reported by Sharma $\mathrm{T}$ et al, (16.6\%) adherence in Dehradoon in India. ${ }^{14}$ In present study hospital was in close proximity to the patients which could be one of the grounds for adherence and the methods used in assessing the adherence to medication and the health care delivery system in different areas could partly explain the differing rates of compliance.

The prevalence of adherence to medications in males (46.05\%) in comparison to females $(38 \%)$ was good but that was not statistically significant. This finding is line with the most of the previous studies Sajith M et al, (Pune), Jemal A et al, (Eastern Ethopia). ${ }^{7,15}$ Mostly females are less educated in comparison to males, they have limited knowledge towards their disease, medications and complications related to discontinuation of drugs leads to their being careless. And because of less literacy they are unable to understand dosing, frequency of drug intake. Rao CR et al, (Karnataka), Gelaw BK et al, (Ethiopia), Hadiyah TM et al, (Sudan) reported female patients have better adherence. $^{12,16,17}$
In present study adherence in diabetic patients are higher in age group 18-40years. This finding is line with the most of previous studies Hadiyah TM et al, (Sudan) reported higher adherence among people above 60years of age and in 30-39years. ${ }^{17}$ Elsous A et al, reported old age ( $\geq 60$ years) was a predictor of good adherence, but the finding was not statistically significant. ${ }^{18}$ It is also important to note that the social support system among the families to take full responsibility for regular medications for the elderly is contributory to good medication adherence. However, diabetes drug therapy is more complex, and patients are required to have more composite cognitive skills to be able to understand the prescribed drug therapy and to adhere to treatment for diabetes mellitus which could be the reason for adherence in age group of 18-40 years as shown in present study.

In the present study T2DM patients with pharmacotherapeutic adherence with duration of diabetes <5years $(49.15 \%), \quad 5-10$ years $(31.82 \%)$, >10years $(47.83 \%)$ were observed which was line with Jemal A et al, (Eastern Ethiopia), Gelaw BK et al, (Ethiopia). ${ }^{15,16}$ This finding was consistent with the study from UAE and India indicating a negative relationship between the duration of diabetes and patient adherence to drug therapy. During the early stage (0-5 years) of the disease patients tend to be more committed to their disease, but their commitment does not last long (5-10years) since they adapt the load and deterioration continues while patients with longer duration (>10years) of disease have gained more experience with disease, established a better physician-patient relationship and had greater belief on physicians' advice. In addition, they might become more knowledgeable about their own health condition and the appropriate management of disease control.

The identified causes of non- adherence to taking medications as prescribed were forgetfulness, carelessness, when felt worse and when felt better while taking medications were found to be $13.52 \%, 13.09 \%, 28.86 \%$ and $14.34 \%$, respectively in current study which are in line with the study of Sajith M et al, (Pune). ${ }^{7}$

Hadiyah TM et al, (Sudan), Arifulla M et al, (UAE), reported forgetfulness was one of the commonly mentioned reasons for non-adherence, which could be overcome by using different measures like informing family members to remind and using alarm. ${ }^{17,19}$ Intentional omission of doses was the next factor. Patients omit the doses of their medications simply because the medications run out or they go elsewhere from home. The other common factors causing non-adherence in this study was lack of finance. ${ }^{17}$

\section{CONCLUSION}

In present study according to the Morisky's instrument only $42.86 \%$ of the patients were adherent while $57.14 \%$ of the patients were non adherent among the total of 126 diabetic patients, that was statistically insignificant ( $p$ 
$>0.05)$. Among urban population, present study shows that pharmacotherapeutic adherence was $68.75 \%$ among study participants of diabetic patients in class II (upper middle class) of Kuppuswamy scale of socioeconomic status shows more pharmacotherapeutic adherence compared to class III (LOWER middle) i.e. 53.13\%, class IV (upper lower class) i.e. $33.93 \%$ that was statistically significant ( $p$ $<0.05$ ). In present study, the major reasons found for medication non-adherence were forgetfulness, followed by them stopped/missed the medication when he or she felt better followed by them stopped/missed the medication when he or she felt worse while taking medicines and followed by carelessness.

\section{ACKNOWLEDGEMENTS}

Authors would like to thank to the Principal G.S.V.M. Medical College, Kanpur and Head of Department of Pharmacology are gratefully acknowledged for providing the necessary facilities to undertake this research work.

\section{Funding: No funding sources}

Conflict of interest: None declared

Ethical approval: The study was approved by the Institutional Ethics Committee

\section{REFERENCES}

1. Sabate E. WHO Adherence Meeting Report. Geneva, World Health Organization, 2001. Available at: http://apps.who.int/iris/bitstream/handle/10665/66984 /WHO_MNC_CCH_01.02.pdf?sequence=1\&isAllow ed=y.

2. World Health Organization, Global Report on Diabetes. Geneva, 2016. Available at: http://en.m.wikipedia.org/wiki/Epidemiology-ofdiabetes-mellitus. Accessed 12 October 2018.

3. Simple treatment to curb diabetes. Available at: https://web.archieve.org/web/20140202134207/http:// www.thejakartapost.com/bali-daily/2014-0120/simple-treatment-curb-diabetes.html. Assessed 10 October 2018.

4. Wild S, Roglic G, Green A, Sicree R, King H. Global prevalence of diabetes: estimates for the year 2000 and projections for 2030. Diabetes Care. 2004 May $1 ; 27(5): 1047-53$.

5. Diabetes can be controlled in 80 percent of Cases in India. Indo-Asian News Service. Available at: news.biharprabha.com. Accessed 6 February 2014.

6. Sontakke S, Jadhav M, Pimpalkhute S, Jaiswal K, Bajait C. Evaluation of adherence to therapy in patients of type 2 diabetes mellitus. J Young Pharmacists. 2015 Oct 1;7(4):462-9.

7. Sajith M, Pankaj M, Pawar A, Modi A, Sumariya R. Medication adherence to antidiabetic therapy in patients with type 2 diabetes mellitus. Int $\mathbf{J}$ Pharm Pharm Sci. 2014;(6), Suppl 2: 564-570.

8. Rickles N, Brown T, McGivney M, Snyder M, White $\mathrm{K}$. Adherence A review of education research practice and policy in the United States. J Pharm Pract. 2010;8:1-17.

9. Lee CS, Tan JH, Sankari U, Koh YL, Tan NC. Assessing oral medication adherence among patients with type 2 diabetes mellitus treated with polytherapy in a developed Asian community: a cross-sectional study. BMJ Open. 2017 Sep 1;7(9):e016317.

10. Huber CA, Reich O. Medication adherence in patients with diabetes mellitus: does physician drug dispensing enhance quality of care? Evidence from a large health claims database in Switzerland. Patient Preference and Adherence. Dovepress. 2016;10:1803-1809.

11. Navya CJ, Naveen R, Ashwini GS, Manu A, Steve J, Singh $\mathrm{J}$, et al. Adherence to Medication among patients with hypertension and diabetes mellitus in selected tea estates in South India. JIMSA. 2015;28(1):16-7.

12. Rao CR, Kamath VG, Shetty A, Kamath A. Treatment compliance among patients with hypertension and type 2 diabetes mellitus in a coastal population of Southern India. Int J Preventive Med. 2014 Aug;5(8):992-8.

13. Abebaw M, Messele A, Hailu M, Zewdu F. Adherence and associated factors towards antidiabetic medication among type II diabetic patients on follow-up at University of Gondar Hospital, Northwest Ethiopia. Adv Nursing. 2016;2016.

14. Sharma T, Kalra J, Dhasmana DC, Basera H. Poor adherence to treatment: a major challenge in diabetes. JIACM. 2014;15(1):26-9.

15. jemal a, abdela $\mathrm{j}$, sisay $\mathrm{m}$. adherence to oral antidiabetic medications among type 2 diabetic (T2DM) patients in chronic ambulatory wards of Hiwot Fana specialized university hospital, Harar, Eastern Ethiopia: a cross sectional study. J Diabetes Metab. 2017;8(1):721.

16. Gelaw BK, Mohammed A, Tegegne GT, Defersha AD, Fromsa M, Tadesse E, et al. Nonadherence and contributing factors among ambulatory patients with antidiabetic medications in Adama Referral Hospital. J Diab Res. 2014;2014.

17. EI-Hadiyah TM, Madani AM, Abdelrahim HM, Yousif AK. Factors affecting medication non adherence in type 2 Sudanese diabetic patients. Pharmacol Pharmacy. 2016 Apr 14;7(04):141.

18. Elsous A, Radwan M, Al-Sharif H, Abu Mustafa A. Medications adherence and associated factors among patients with type 2 diabetes mellitus in the Gaza Strip, Palestine. Frontiers Endocrinol. 2017 Jun 9;8:100.

19. Arifulla M, Lisha Jenny JO, Sreedharan J, Muttappallymyalil J, Basha SA. Patients' adherence to anti-diabetic medications in a hospital at Ajman, UAE. Malaysian J Med Sci. 2014 Jan;21(1):44-9.

Cite this article as: Gaur R, Kushwaha V, Agrawal P, Agrawal S, Kumar A, Malhotra K. A cross sectional study to assess pharmacotherapeutic adherence among diabetes mellitus patients in tertiary care hospital. Int J Basic Clin Pharmacol 2019;8:216-21. 